\title{
The effect of different additives on safety manipulation of cis- 1,3,4,6-tetranitrooctahydroimidazo-[4,5-d]imidazole (BCHMX)
}

\author{
Ahmed K. HUSSEIN ${ }^{1 *}$, Ahmed ELBEIH ${ }^{2}$, Svatopluk ZEMAN ${ }^{1}$, Marcela JUNGOVA ${ }^{1}$ \\ ${ }^{1}$ Institute of Energetic Materials, Faculty of Chemical Technology, University of Pardubice, Czech Rep. \\ ${ }^{2}$ Military Technical College, Kobry Elkobbah, Cairo, Egypt
}

\begin{abstract}
In this work, new cyclic nitramine named cis-1,3,4,6-tetranitrooctahydroimidazo-[4,5d]imidazole (BCHMX) was premixed with insensitive explosives (3-nitro-1,2,4-triazol-5-one, NTO and 1,1-diamino-2,2-dinitroethene, FOX) and with two cyclic nitramines (1,3,5-trinitro-1,3,5-triazinane, RDX and, 1,3,5,7-tetranitro-1,3,5,7-tetrazocane, HMX) and bonded by polydimethyl-siloxane (PDMS) binder. Impact and friction sensitivities were evaluated. Detonation velocity was measured and the detonation characteristics were calculated by EXPLO 5 thermodynamic code. Relative explosive strength was determined by using the ballistic mortar test. The results showed a great positive influence on the sensitivity of BCHMX due to the addition of the insensitive explosive (NTO, FOX-7) however the performance was decreased. On the other side, mixing the nitramines improved the performance with reduction of BCHMX sensitivity. PDMS binder succeed to decrease the sensitivity of all the studied mixtures.
\end{abstract}

\section{Introduction}

An interesting explosive, cis-1,3,4,6Tetranitrooctahydroimidazo-[4,5-d]imidazole (BCHMX) was prepared in the laboratory of the Institute of energetic materials as reported in Czech patent [1]. The performance of BCHMX was determined in comparison with several traditional explosives [2-4]. It has detonation performance in the level of HMX while it has high sensitivity similar to penterythritol tetranitrate (PETN) [5]. Reduction of its sensitivity is still considered a challenge. BCHMX was coated by different polymeric matrices in order to reduce the sensitivity without affecting its thermal stability [6-8]. polydimethyl-siloxane (PDMS) matrix seems to be an optimum binder for coating the explosive crystals: it has the ability to reduce the sensitivity of the explosives to acceptable level in addition to keep the detonation heat in the range of Plastic bonded explosives (PBXs) based on poly-fluorinated polymers [6]. After the addition of insensitive explosive such as 3-nitro-1,2,4-triazol-5-one, (NTO) or 1,1-diamino-2,2-dinitroethene (FOX-7), the sensitivity was improved significantly and reached the level of LOVA mixture (Ontallite; 50\% TNT:50\%NTO) $[9,10]$. Consequently, in this paper and with the same vein, BCHMX was mixed with other nitramines explosive (1,3,5-trinitro-1,3,5-triazinane, RDX and, 1,3,5,7-tetranitro-1,3,5,7-tetrazocane, HMX) and bonded in PDMS. Their characteristics were studied and compared with the previous literature data.

\section{Experimental work}

\subsection{Materials and preparation method}

BCHMX was prepared at our institute where white crystals were obtained. NTO was prepared by adding formic acid to semicarbazide hydrochloride followed by the nitration using mixed acid as discussed in ref. [11]. FOX-7 is yellow crystals prepared by nitrating 2methylpyrimidine-4,6-diol then the hydrolysis of intermediate 2-(dinitromethylidene)-5,5-dinitrodihydro pyrimidine-4,6(1H,5H)-dione to obtain FOX-7 [12]. Two types of polydimethylsiloxane (PDMS) were used $\left(\right.$ Wacker $\left.^{\circledR} \mathrm{AK} 10000\right)$ and $\left(\right.$ Wacker $\left.{ }^{\circledR} \mathrm{AK} 60000\right)$. A ratio of 1:1 of these two kinds were used in order to produce the required average molecular mass and viscosity. The weight of energetic filler was $88 \%$ and in the mixture (44\% of BCHMX and $44 \%$ of other explosive) and the binder was $12 \%$. Plastograph was used to prepare the samples and they were designed as BCHMX-Sil, BCHMX/NTO-Sil, BCHMX/FOX7-Sil, BCHMX/RDX-Sil, BCHMX/HMX-Sil.

\subsection{Sensitivity to impact and friction}

BAM impact sensitivity instrument [13] with exchangeable drop weight were used. Hammers with different weights were used from different heights to determine the impact energy required for initiation of the explosives. While BAM friction test apparatus was used to determine the friction sensitivity of the samples by spreading the material on a porcelain plate with rough surface. The normal force between the porcelain pistil and the plate was changed using different loads. The 
$50 \%$ probability of initiation (H50) was determined for each sample based on the Probit analysis technique[14]. The results of the sensitivity measurements are reported in Table 1.

\subsection{Detonation velocities measurements}

The detonation velocitites of all the studied samples were obtained by using EXPLOMET-FO-2000 device (KONTINITRO AG). The tested samples were prepared on the form of cylindrical shape with $21 \mathrm{~mm}$ diameter and $20 \mathrm{~cm}$ length. Three optical probs were inserted inside each charge where the first prob was placed at 5 $\mathrm{cm}$ from the side with the detonator. The other two probs were inserted at a distance of $6 \mathrm{~cm}$ from the previous one. detonator no. 8 was used to initiate the charges. Three testes were pursuance for each sample. The mean value of each tested sample was reported in Table 2.

\subsection{Detonation characteristics calculations}

The main theoretical characteristics of detonation (velocity of detonation, D, pressure of detonation, $\mathrm{P}$, and detonation heat, Q,) for all the studied samples were determined by EXPLO5 V 5.04 thermodynamic code [15]. BKWN set of parameters was applied in this study: $\alpha=0.5, \beta=0.176, \kappa=14.71, \Theta=6620$ [15]. The results of the theoretical calculation in comparison with the measured values are reported on Table 2 .

\subsection{Relative explosive strength measurements}

Determination of the relative explosive strength for all the prepared samples, with respect to TNT, were done by using the ballistic mortar $[13,16] .10 \mathrm{~g}$ of each sample was prepared and placed inside the ballistic mortar where the projectile locked the sample then fired by plain detonator. The results are reported in table 2 as the relative explosive strength compared to TNT [16].

\section{Results and discussion}

The performance of explosive material has a significant effect on its impact and friction sensitivity which was represent in recently accepted literatures [6, 17], at which, the high performance of explosive is accompanied by an increase of explosive sensitivity. However, modern techniques are used to discuss the relation between the performance and the reduction of sensitivity. Therefore, the plastic explosive mixture is one of the methods to combine between the performance and the sensitivity reduction. Moreover, presence of different explosive on the bimodal system in the PBXs has another effect on both sensitivity and performance. With a view to the sensitivity of the tested samples, a comparison between impact sensitivity (initiation due to uniaxial compression) and friction sensitivity (initiation due to shear slide of a fixed volume) of all the studied samples are shown in Fig. 1.

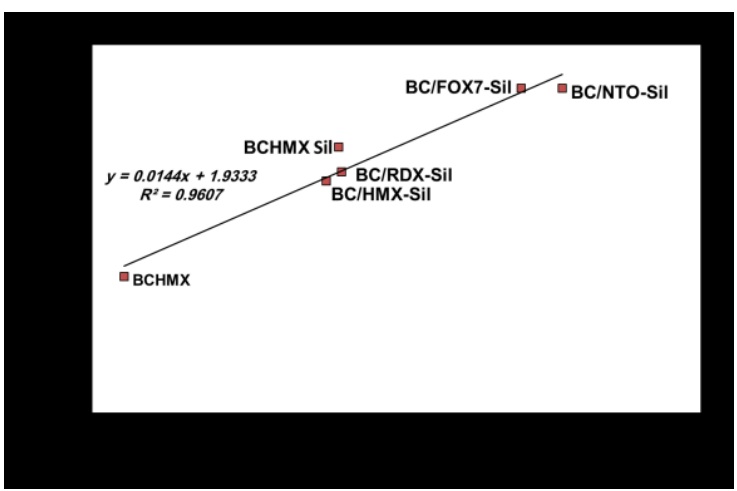

Fig. 1: Relation between Logarithm of friction and impact sensitivity

It was observed that the samples could be classified according to their sensitivity to two groups. The First group; mixture of BCHMX with nitramine and individual BCHMX in PDMS. The second group: mixture of BCHMX with FOX-7 and NTO.

The first group is more sensitive compared with second group. Regarding to the first group; BCHMX-Sil is the less sensitive to both impact and fiction compared with the mixtures with RDX and HMX, nevertheless, $\mathrm{BC} / \mathrm{RDX}-\mathrm{Sil}$ has the same value in impact sensitivity with BCHMX-Sil and still slightly sensitive to friction. For the second group; the mixtures BC/FOX7-Sil and $\mathrm{BC} / \mathrm{NTO}-\mathrm{Sil}$ are the less sensitive $\mathrm{PBX}$ among all the studied composition however BC/NTO-Sil is still less sensitive than $\mathrm{BC} / \mathrm{FOX} 7-$ Sil toward impact impulse.

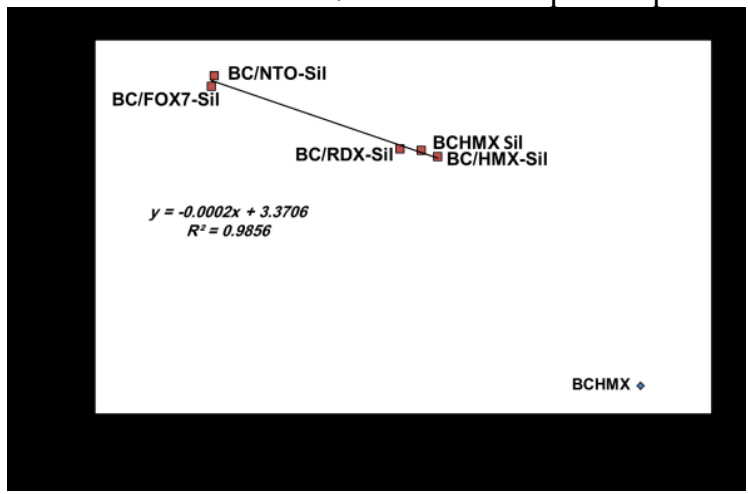

Fig. 2: Semi-logarithmic relationship between impact sensitivity and volume heat of explosion

An interesting relationship between volume heat of explosion (the product of loading density and the volume explosion heat $\rho . Q / \mathrm{MJ} . \mathrm{m}^{-3}$ ) compared with the logarithm of impact sensitivity [18, 19] is presented in Fig. 2. Confirmation with what Licht [20] has pointed out, increasing the explosive performance is usually accompanied by an increase in the sensitivity $[3,6,20]$ and cannot be proved by any theory. This relationship gave a clear approve with Licht and explain how less performance of BC/NTO-Sil and BC/FOX7-Sil are less sensitive than the other mixtures. However, It is also obvious here that $\mathrm{BC} / \mathrm{HMX}$-Sil the more sensitive and has the highest performance among the studied samples. It is also clear that the BCHMX is outside the line connected the studied PBXs, it is due to BCHMX is a pure explosive and has high performance and high sensitivity. 
Table 1. Performance and detonation parameters of the samples studied

\begin{tabular}{|c|c|c|c|c|c|c|}
\hline No & Code designation & Summary formula & $\begin{array}{c}\text { Heat of } \\
\text { combustion } \\
{\left[{\left.\mathrm{J} . \mathrm{g}^{-1}\right]}^{-1}\right.}\end{array}$ & $\begin{array}{l}\text { Enthalpy of } \\
\text { formation } \\
{\left[\mathrm{kJ} \mathrm{mol}^{-1}\right]} \\
\end{array}$ & $\begin{array}{c}\text { Impact } \\
\text { sensitivity } \\
{[\mathrm{J}]}\end{array}$ & $\begin{array}{c}\text { Friction } \\
\text { sensitivity } \\
{[\mathbf{N}]}\end{array}$ \\
\hline 1 & BCHMX & $\mathrm{C}_{4} \mathrm{H}_{6} \mathrm{~N}_{8} \mathrm{O}_{8}$ & 9124 & 236.5 & $3.2^{\mathrm{a}}$ & $88^{\mathrm{a}}$ \\
\hline 2 & BCHMX-Sil. & $\mathrm{C}_{5.02} \mathrm{H}_{9.18} \mathrm{~N}_{8} \mathrm{O}_{8.47} \mathrm{Si}_{0.54}$ & 11328 & -27.16 & $24.3^{\mathrm{a}}$ & $232^{\mathrm{a}}$ \\
\hline 3 & BCHMX/NTO-Sil & $\mathrm{C}_{2.42} \mathrm{H}_{2.99} \mathrm{~N}_{4.84} \mathrm{O}_{4.2} \mathrm{Si}_{0.81}$ & 9512 & -80.5 & $46.3^{b}$ & $>360^{\mathrm{b}}$ \\
\hline 4 & BCHMX/FOX7-Sil & $\mathrm{C}_{4.52} \mathrm{H}_{9.82} \mathrm{~N}_{6} \mathrm{O}_{7.36} \mathrm{Si}_{0.446}$ & 11863 & -286.5 & 42.3 & $>360$ \\
\hline 5 & BCHMX/RDX-Sil & $\mathrm{C}_{4.60} \mathrm{H}_{9.60} \mathrm{~N}_{7.0} \mathrm{O}_{4.56} \mathrm{Si}_{0.53}$ & 11951 & -93.8 & 24.6 & 192.7 \\
\hline 6 & BCHMX/HMX-Sil & $\mathrm{C}_{5.50} \mathrm{H}_{11.45} \mathrm{~N}_{8.0} \mathrm{O}_{9.01} \mathrm{Si}_{0.63}$ & 1.64 & -135.7 & 23.1 & 179.7 \\
\hline
\end{tabular}

a) $[6] ;$ b) [10]

Table 2. Results of the experimental measurements on the samples studied

\begin{tabular}{|c|c|c|c|c|c|c|c|c|c|}
\hline \multicolumn{2}{|c|}{ Studied sample } & \multicolumn{3}{|c|}{ Experimental } & \multicolumn{5}{|c|}{ Calculated detonation parameters by Explo5 } \\
\hline \multirow[t]{2}{*}{ No. } & \multirow[t]{2}{*}{ Code of samples } & \multirow{2}{*}{$\begin{array}{l}\text { Density } \\
\rho \\
{\left[\text { g.cm }^{-3}\right]}\end{array}$} & \multirow[t]{2}{*}{$\begin{array}{l}\text { RS } \\
\% \text { TNT }\end{array}$} & \multirow[t]{2}{*}{ Ref. } & \multicolumn{2}{|c|}{$\begin{array}{l}\text { Detonation velocity } \\
{\left[\mathrm{m} . \mathrm{s}^{-1}\right]}\end{array}$} & \multirow[t]{2}{*}{$\begin{array}{l}\text { Error } \\
\%\end{array}$} & \multirow{2}{*}{$\begin{array}{l}\text { Detonation } \\
\text { pressure } \\
\mathbf{P} \\
{[\text { GPa] }}\end{array}$} & \multirow{2}{*}{$\begin{array}{l}\text { Detonation } \\
\text { heat } \\
\text { Q } \\
{\left[\mathbf{k J . k g}^{-1}\right]}\end{array}$} \\
\hline & & & & & $D_{\text {exp }}$ & $D_{\text {cal. }}$ & & & \\
\hline 1. & BCHMX & 1.79 & - & [2] & 8650 & 8840 & +2.19 & 33.9 & 6447 \\
\hline 2. & BCHMX-Sil. & 1.62 & 137.5 & [10] & 7994 & 7742 & -2.82 & 24.2 & 6245 \\
\hline 3. & BCHMX/NTO-Sil & 1.61 & 112.2 & [10] & 7864 & 7719 & -1.84 & 23.7 & 5450 \\
\hline 4. & BCHMX/FOX7-Sil & 1.59 & 123.5 & [9] & 7889 & 7438 & -5.71 & 21.3 & 5507 \\
\hline 5. & BCHMX/RDX-Sil & 1.61 & 137.8 & & 7712 & 7633 & -1.02 & 23.3 & 6197 \\
\hline 6. & BCHMX/HMX-Sil & 1.64 & 137.3 & & 7834 & 7739 & -1.21 & 24.3 & 6234 \\
\hline
\end{tabular}

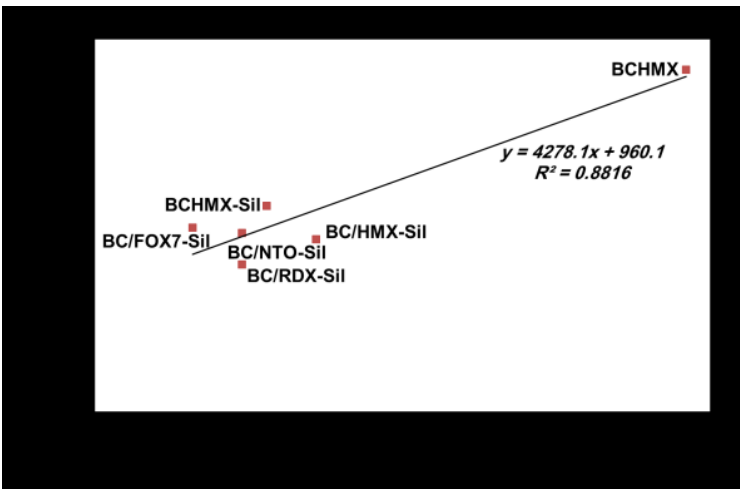

Fig. 3: A relationship between the density and the detonation velocity of all the studied explosives

The measured densities and detonation velocities were recorded in Table 2 and the results were presented on Fig. 3 where the well-known relationship between the density and the detonation velocity was confirmed. The BCHMX has the highest detonation velocity of the studied samples and as predicted the silicone matrix decreased the detonation velocity.

The detonation velocity of individual explosive BCHMX in PDMS has the higher detonation in spite of the lower density than the BC/HMX-Sil. This reason might be due to heterogeneity in the matrix. In the other way, the $\mathrm{BC} / \mathrm{FOX} 7-\mathrm{Sil}$ has the lower density and has detonation velocity slightly lower than BCHMX-Sil (by $105 \mathrm{~m} \mathrm{~s}^{-1}$ ). It is also obvious that addition of other explosive in the mixture with the BCHMX in the PBX matrix has reduced the detonation velocity.

Fig.4 presents a relationship between the volume heat of detonation, calculated by EXPLO5 (here $Q$ in $\mathrm{kJ} \mathrm{kg}^{-1}$ ) and the relative explosive strength ( $\%$ of TNT) measured by ballistic mortar. From Fig.4, the logical dependence of the relative explosive strength on the heat of detonation was confirmed.

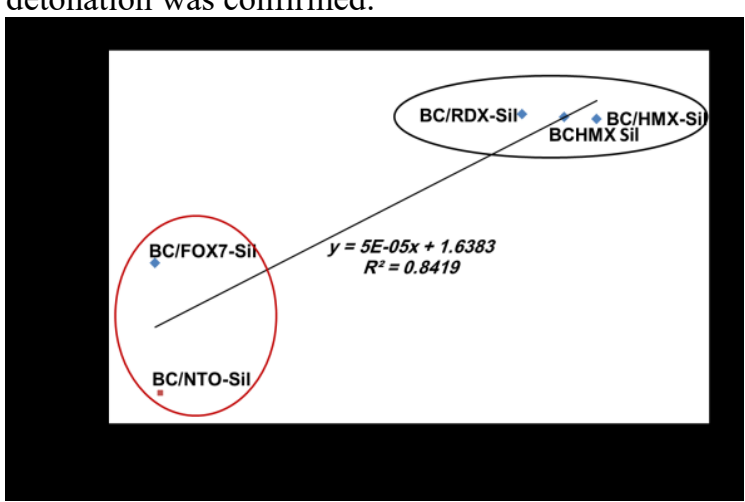

Fig. 4: Relationship between relative explosive strength and volume heat of detonation ( $\mathrm{Q}$ in $\mathrm{kJ} \mathrm{kg}^{-1}$ was calculated by the EXPLO5 code) of the studied PBXs.

BC/FOX7-Sil, BC/NTO-Sil have the relative strength of 123 and $112.2 \%$ of TNT respectively while BC/HMXSil, BC/RDX-Sil and BCHMX-Sil have the relative strength of $137.3,137.8$ and $137.5 \%$ of TNT respectively which confirm the high performance of the PBX however, BC/FOX7-Sil, BC/NTO-Sil have the lower performance among the studied samples, This is clear, as these two PBX have the heat of detonation of. 5507 and $5450 \mathrm{~kJ} \mathrm{~kg}^{-1}$ respectively. This behavior mainly comes from the FOX-7 and NTO which act as coolant for the gases generated and reduces the performance [10].

\footnotetext{
Corresponding author: ahmed92egypt@,gmail.com
} 


\section{Conclusion}

A relative sensitive explosive cis-1,3,4,6tetranitrooctahydroimidazo-[4,5- $d$ ] imidazole (BCHMX) is possible to be stabilized against mechanical impulses by incorporation into polydimethylsiloxane matrix (PDMS). However, using of the other explosive mixed with BCHMX in this matrix play a backbone in the sensitivity. The overall results confirm that mixing of FOX-7 and NTO with BCHMX in PBX bonded by Silicone matrix reduced the sensitivity of BCHMX significantly However, mixing of HMX with BCHMX slightly improve the performance but with increase of sensitivity in the same time. While mixing of RDX with BCHMX slightly decrease the performance and improve sensitivity. The calculated detonation characteristics of PBX by EXPLO5 thermodynamic code are compatible with the experimental values.

\section{Acknowledgement}

This paper was supported by means of the financial resources of Students Grant Projects No. SGSFCHT_2016002 of the Faculty of Chemical Technology at the University of Pardubice.

\section{References}

1. D. Klasovitý, S. Zeman, Czech Pat, 302068 (2010).

2. A. Elbeih, M. Mokhtar Mohamed, T. Wafy, Pro., Expl., Pyro., 41 (2016) 1044-1049.

3. A. Elbeih, T.Z. Wafy, T. Elshenawy, Cent. E. J. Energ. Mat., 14 (2017) 77-89.

4. W. Pelikán, S. Zeman, Q.L. Yan, M. Erben, A. Elbeih, Z. Akštein, Cent. E. J. Energ. Mat., 11 (2014).

5. A. Elbeih, T. Elshenawy, M. Gobara, Def. Sci. J., 66 (2016) 499.

6. A. Elbeih, S. Zeman, M. Jungova, P. Vávra, Z. Akstein, Pro., Expl., Pyro., 37 (2012) 676-684.

7. S. Zeman, Q.-L. Yan, A. Elbeih, Cent. E. J. Energ. Mat., 11 (2014) 395--404.

8. Q.-L. Yan, S. Zeman, P. Sánchez Jiménez, T.-L. Zhang, L. Pérez-Maqueda, A. Elbeih, J. Phy. Chem. C, 118 (2014) 22881-22895.

9. A.K. Hussein, A. Elbeih, M. Jungova, S. Zeman, Pro., Expl., Pyro.(2018)

10. A.K. Hussein, A. Elbeih, S. Zeman, Therm. Acta, 655 (2017) 292-301.

11. A.K. Nandi, S.K. Singh, G.M. Kunjir, J. Singh, A.K. Mandal, R.K. Pandey, Cent. E. J. Energ. Mat., 10 (2013).

12. J. Ottis, Z. Jalový, F. Liška, J. Energ. Mat., 26 (2008) 220-229.

13. M. Suceska, Testing Methods of Explosives, in, Springer, Heidelberg, (1995).

14. J. Šelešovský, J. Pachmáň, Cent. E. J. Energ. Mat., 7 (2010) 269-278.

15. M. Sućeska, Mat. Sci. Forum, Trans Tech Publ, 2004, pp. 325-330.
16. Notice of Czech Mining Authority No. 246/1996 of Law Collect, Establishing More Detailed Conditions for Allowing Explosives, Explosive Objects and Aids in Use, and their Testing, 1996.

17. A. Elbeih, S. Zeman, M. Jungova, Z. Akstein, Cent. E. J. Energ. Mat., 9 (2012) 131-138.

18. M. Jungová, S. Zeman, A. Husarová, Chiense J. Energ. Mat., 19 (2011).

19. A. Elbeih, S. Zeman, Cent. E. J. Energ. Mat., 11 (2014).

20. [20] H.-H. Licht, Pro., Expl., Pyro., 25 (2000) 126132. 